\title{
Influence of the Distribution of Excess Carbide on the Properties of Genuine Damascus Steel
}

\author{
Dmitry Sukhanov ${ }^{*}$, Nataliya Plotnikova ${ }^{2}$ \\ ${ }^{1}$ ASK-MSC Company (Metallurgy), Moscow, Russia \\ ${ }^{2}$ Novosibirsk State Technical University, Novosibirsk, Russia \\ Email: *suhanov7@mail.ru, n.plotnikova@corp.nstu.ru
}

How to cite this paper: Sukhanov, D. and Plotnikova, N. (2019) Influence of the Distribution of Excess Carbide on the Properties of Genuine Damascus Steel. Materials Sciences and Applications, 10, 118-136. https://doi.org/10.4236/msa.2019.102010

Received: December 11, 2018

Accepted: January 27, 2019

Published: January 30, 2019

Copyright $\odot 2019$ by author(s) and Scientific Research Publishing Inc. This work is licensed under the Creative Commons Attribution International License (CC BY 4.0).

http://creativecommons.org/licenses/by/4.0/

(c) (i) Open Access

\begin{abstract}
The methods of spectral, $\mathrm{x}$-ray phase and microprobe analysis show that genuine Damascus steel is a high-purity unalloyed high-carbon steel with a high phosphorus content. It is shown that phosphorus in an amount of from $0.1 \%$ to $0.2 \%$, having a high liquation coefficient, contributes to the process of segregation of carbon in interdendritic zone in the process of crystallization. Interdendritic zone formed carbon clusters, in the process of forging transform into oblong carbides cementite. The main physical and chemical factors affecting the formation of oblong carbides are revealed. The hardness of carbide layers was determined, which was about $920 \mathrm{HV}$. The hardness of the troostite matrix was amounted about $475 \mathrm{HV}$. It is established that the cutting edge of the blade knife of Damascus steel is nothing more than a "micro-saw" consisting of parallel carbide and troostite layers. Tests are conducted on the preservation of the cutting edge sharpness of the blades knife of homogeneous structure of steel Y15A (Russian) and the layered structure of genuine Damascus steel Ds15P (Indo-Persian). Found that with little effort cut (to $4 \mathrm{~kg}$ ) ancient Damascus steel (Ds15P) shows a greater number of cuts than the modern instrument steel $\mathrm{Y} 15 \mathrm{~A}$. With an increase, force on the cutting edge from $6 \mathrm{~kg}$ to $12 \mathrm{~kg}$ carbon Tool steel is showed a more number of cutting on the $25 \%$ than in genuine Damascus steel. The fatigue crack propagation in the true Layered structure of Damascus steel Ds15P occurs for a greater number of cycles than in a homogeneous structure of the steel $\mathrm{Y} 15 \mathrm{~A}$. The blade knife of genuine Damascus steel, in terms of fatigue reliability (survivability), has almost 2 times longer service life than the blade knife of the modern carbon tool steel type $\mathrm{Y} 15 \mathrm{~A}$. It is proved that loss in cutting ability of a genuine Damascus steel compensates increased the reliability ("survivability") of the blade knife with fatigue loads.
\end{abstract}




\section{Keywords}

Carbon Tool Steels, Genuine Damascus Steel, Wootz Steel, Bulat Steel, Indo-Persian Steel

\section{Introduction}

Mass production of Indo-Persian steel for the manufacture of chopping edged weapons dates back to the XVII-XIX centuries. On an industrial scale, genuine Damascus steel is no longer produced. Knife blades of modern dressing are made only in the handicraft way in piece quantities. This is due to the design feature of products made of genuine Damascus steel, which is based on the carbide heterogeneity of the structure.

Modern tool makes production of carbide heterogeneity as marriage. Uniform distribution of hardness over the entire working surface of carbon tool steels is the main requirement in the manufacture of semi-finished products in the form of calibrated circles and hexahedron. What is considered as a marriage in carbon tool steels can be an advantage in blade products made of genuine Damascus steel.

In this area of research of little-studied issues, first, the physicochemical factors affecting the formation of the morphology of the excess carbide phase peculiar only to the Eastern blades of genuine Damascus steel are not clarified. Secondly, the nature of the destruction of genuine Damascus steel under fatigue load, which determines the reliability of the blade knife product under long alternating loads, has not been established. Thirdly, there is no understanding basic of the advantages and disadvantages in the process of operation of the blade weapons made of genuine Damascus steel.

The purpose of this work was to show the main advantages and disadvantages of the blade products of genuine Damascus steel in comparison with modern carbon tool steels containing the same amount of carbon (about 1.5\%carbon).

\section{Materials and Methods}

As materials for the study is the fragment tip of the blade knife of genuine Damascus steel (marking Ds15P), about $50 \mathrm{~mm}$ long (Figure 1(a)) and an industrial circle made of carbon Tool steel (marking Y15A), which is produced according to the standard, were chosen GOST 1435-99 (in Russian) (Figure 1(b)).

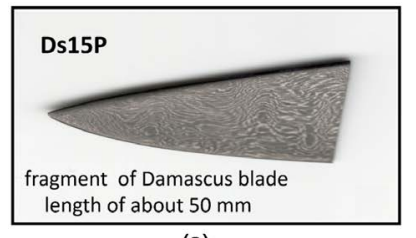

(a)

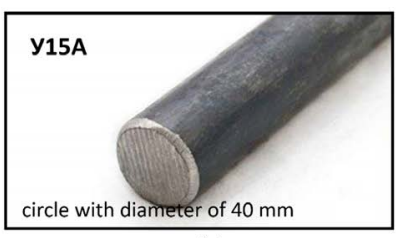

(b)

Figure 1. Research materials: (a) genuine Damascus steel; (b) carbon Tool steels. 
It was not possible to establish the era of making a Damascus blade on the fragment of the tip of the knife blade. After polishing and etching in $4 \%$ ethyl alcohol solution of nitric acid on the side surface of the genuine Damascus blade showed a contrasting pattern on a black background of the steel matrix.

Steel y15A (in Russian) in the production of knife blades is very rare. This steel is difficult in the machining, it has an increased fragility after quenching, and it has a low heat resistance of carbides. These factors are the main drawbacks of carbon Tool steels of type Y15A compared to chromium tool steels of type X12M (in Russian). In the industry of steel y15A made files, taps, reamers, working at relatively low cutting speeds. The heating temperature of the tool should not exceed $200^{\circ} \mathrm{C}$. Carbon tool steels is not used for welded structures.

The chemical composition of steel y15A and genuine Damascus steel Ds15P was determined using an optical emission spectrometer type ARL 3460 (Figure 2).

In the analysis of the chemical composition of genuine Damascus steel (Ds15P) observed that the sample is virtually no residues of deoxidation products: silicon is $0.082 \% \mathrm{Si}$; manganese is $0.006 \% \mathrm{Mn}$; aluminum is $0.004 \% \mathrm{Al}$. Discovered excessive levels of phosphorus about $0.19 \%$ P. The Percentage of phosphorus in tens of times exceeds the threshold value for high carbon tool steel type $\mathrm{y} 15 \mathrm{~A}$. The low content carbide-forming elements (chromium is $0.001 \% \mathrm{Cr}$; vanadium is $0.011 \% \mathrm{~V}$; cobalt is $0.015 \% \mathrm{Co}$; tungsten is $0.002 \% \mathrm{~W}$; niobium is $0.004 \% \mathrm{Nb}$; titanium is $0.002 \% \mathrm{Ti}$ ) could not significantly affect the formation of carbide components in genuine Damascus steel. Thus, genuine Damascus steel type Ds15P is a carbon tool steel with a high content of phosphorus (about $0.2 \%$ ).

Analysis of the chemical composition of carbon Tool steel ( $\mathrm{Y} 15 \mathrm{~A})$ discovered the remains of a minimum of deoxidation products (silicon is $0.176 \% \mathrm{Si}$; manganese is $0.114 \% \mathrm{Mn}$; aluminum is $0.011 \% \mathrm{Al}$ ) and a minimum content of phosphorus is $0.007 \%$ P. Steel $\mathrm{Y} 15 \mathrm{~A}$ is a perfect physical-mechanical characteristics for comparison of research results with the results of genuine Damascus steel.

Phase analysis of the structure of genuine Damascus steel was performed on the ARL X'TRA $x$-ray diffractometer using a copper $\mathrm{x}$-ray tube as a source of $\mathrm{x}$-ray radiation (voltage $40 \mathrm{kV}$, current $40 \mathrm{~mA}$ ). Quantitative phase analysis and the mass fraction of chemical elements in separate phases of genuine Damascus

\begin{tabular}{|c|c|c|c|c|c|c|}
\hline \multirow{2}{*}{ Steels } & \multicolumn{6}{|c|}{ The content of chemical elements, $\%$} \\
\hline & C & $\mathrm{Mn}$ & Si & $\mathrm{P}$ & $S$ & $\mathrm{Fe}$ \\
\hline Ds15P* & 1.48 & 0.006 & 0.082 & 0.192 & 0.005 & 98.235 \\
\hline $\mathrm{y} 15 \mathrm{~A}^{* *}$ & 1.54 & 0.114 & 0.176 & 0.007 & 0.005 & 98.158 \\
\hline \multicolumn{7}{|c|}{$\begin{array}{l}\text { Deciphering the markings: }{ }^{*} \mathrm{D} s \text { - genuine Damascuss steel; } 15-1.45-1.54 \% \text { carbon; } \\
\text { P - } 0.12 \text { - } 0.22 \text { phosphorus; }{ }^{*} \mathrm{y}-\text { carbon Tool steel; } 15-1.45 \%-1.54 \% \text { carbon; } \\
\text { A - high-quality alloy containing < } 0.03 \% \text { P }\end{array}$} \\
\hline
\end{tabular}

Figure 2. Marking and chemical composition of the studied steels. 
steel were carried out using microstructural studies on the CarlZeiss EV050 XVP scanning electron microscope with the system of probe micro analyzer EDS $\mathrm{X}$-Act and optical microscope series METAM PB-21-2 in the range of magnification from 50 to 1100 crats. To identify the features of the fine structure transmission electron microscope FEI Tecnai G2 20 TWIN was used.

Comparative tests of felt cutting with thickness of $4 \mathrm{~mm}$ on installation with the reciprocating mechanism are carried out. The installation diagram is shown in Figure 3(a). Tests were carried out on triangular specimens with a thickness of $2 \mathrm{~mm}$. The specimen size was $50 \times 20 \times 55 \mathrm{~mm}$. Sharpening angle of $60 \mathrm{de}-$ grees. The sample was attached to the rod performing reciprocating motion due to the rotation of the shaft connected by the coupling to the motor shaft. The load is fixed on the shaft. Changing the weight of the load, is controlled by the amount of force acting through the rod on the sample. That was measured number of cutting (n) at a given load (P) until the sample completely slipped through the felt. The cutting edge after the test is represented in Figure 3(b). The edge was reground at an angle of 60 degrees. The test cycle was repeated.

The reliability of genuine Damascus steel was determined under fatigue conditions. Tests were carried out on flat samples having the dimensions $50 \times 20 \times$ $55 \mathrm{~mm}$, thickness $2 \mathrm{~mm}$. The Diagram of the installation shown in Figure 4(a). The loading of samples was carried out according to the scheme of three-point bending. Imitators of notches on the blade served as incisions depth of $1 \mathrm{~mm}$,

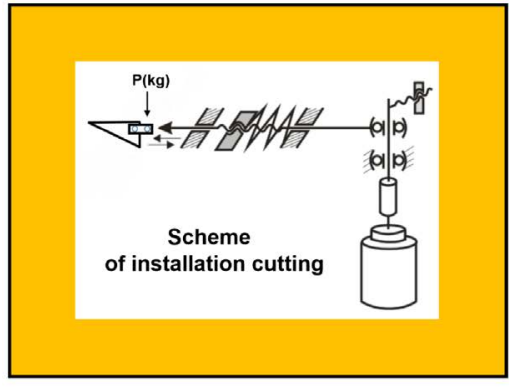

(a)

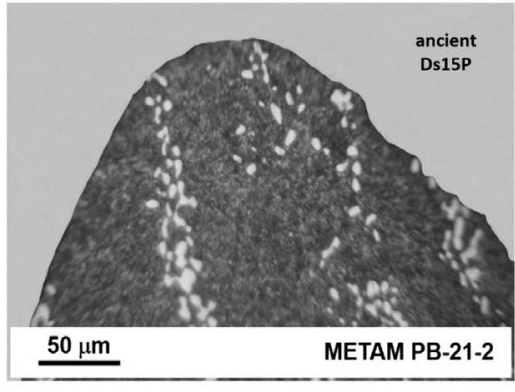

(b)

Figure 3. Test the resistance of the cutting edge: (a) Scheme of installation cutting; (b) Cutting edge after testing.

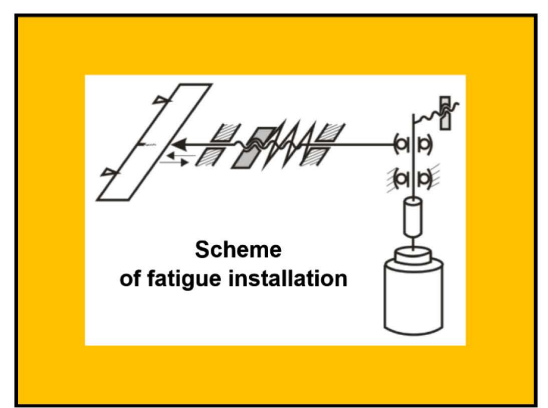

(a)

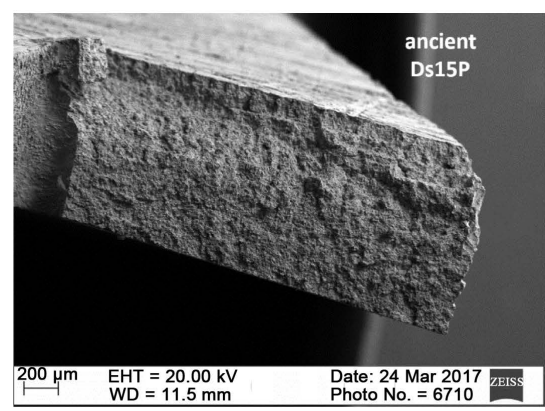

(b)

Figure 4. Test the reliability of the fatigue conditions: (a) Scheme of installation fatigue; (b) Fatigue fracture after testing. 
obtained on the electric spark machine with a brass wire diameter of $0.15 \mathrm{~mm}$. The rod, performing reciprocating motion, carried out the loading of the samples. The rod received movement due to the rotation of the shaft connected by the coupling to the motor shaft. The fatigue crack length $\mathrm{L}(\mathrm{mm})$ was measured in a given number of loading cycles until the specimen was destroyed. The photos fatigue fracture is presented in Figure 4(b).

\section{Results and Discussions}

The main structural difference between genuine Damascus steel (Ds15P) and modern carbon Tool steel type $\mathrm{Y} 15 \mathrm{~A}$ is the heterogeneity of the distribution of excess carbides in the troostite matrix. The heterogeneity of the distribution of carbides is inherent in many tool steels, but only in genuine Damascus blades, it has reached its perfection.

Samples for studies of inhomogeneous structure were cut from a fragment of the knife blade in three directions: from the side of the blade butt (longitudinal direction); from the end side of the blade (transverse direction); from the front side of the blade surface (frontal direction).

In the longitudinal direction occurs a heterogeneous layered structure during the forging of the knife blade (Figure 5(a)). On a dark background of the troostite matrix, light layers from $15 \mu \mathrm{m}$ to $45 \mu \mathrm{m}$ thick are seen, consisting of with oblong cementite particles. The density of the discontinuous carbide layers ranges from 10 to 15 pieces in $1.0 \mathrm{~mm}$. Thickness troostite layers between the carbide layers is in the range from $45 \mu \mathrm{m}$ to $75 \mu \mathrm{m}$. The hardness of the butt of the blade knife is 48 HRC.

In the transverse direction of the blade knife (the edge of the blade), as in the longitudinal direction (the butt of the blade), there is an inhomogeneous layered structure (Figure 5(b)). Dark areas troostite layers have sizes from $45 \mu \mathrm{m}$ to $75 \mu \mathrm{m}$. Between them, there are strips of oblong carbides of cementite, forming layers with sizes from $20 \mu \mathrm{m}$ to $40 \mu \mathrm{m}$. It is estimated that the inhomogeneous-layered structure with a blade knife thickness of at least $2.0 \mathrm{~mm}$ contains about $25-30$ carbide layers. Closer to the cutting edge, where the thickness of the blade knife is not more than $1.5 \mathrm{~mm}$ the number of layers is reduced to $10-15$ pieces. The cutting edge is formed in such a way as to form a "micro-saw" of different types of layers of no more than 6 pieces (Figure 5(b)). The hardness cutting edge

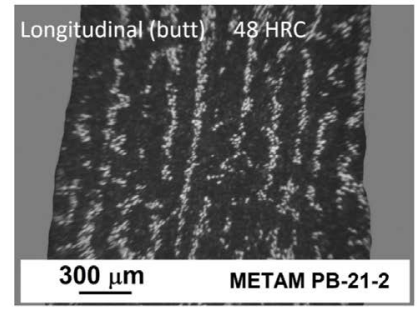

(a)

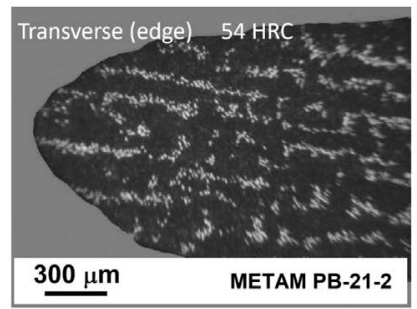

(b)

Figure 5. Structure of the knife blade of genuine Damascus steel (Ds15P): (a) Longitudinal direction (butt); (b) Transverse direction (cutting edge). 
blade knife was not less than 54 HRC. Thus, the hardness near the cutting edge on $12 \%$ is greater than the hardness near the butt.

The frontal direction was of the investigated chemical composition of the dark (troostite) and light (carbide) layers that are clearly observed in the structure of genuine Damascus steel (Figure 6). The method of microprobe chemical analysis revealed segregation areas in which the constant impurities of silicon, phosphorus and sulfur are concentrated. The dark layers of troostite (Spectrum 1 in Figure 6) constitute high purity steel containing $99.11 \% \mathrm{Fe}, 0.86 \% \mathrm{C}$ and $0.03 \%$ Si. Other impurities were not detected. At the interface of the troostite-carbide layers (Spectrum 2 in Figure 6) the impurity concentration of silicon and phosphorus increases from dark troostite layer to light carbide layer. Light carbide layers on chemical composition represent pre-eutectic white cast iron (Spectrum 3 in Figure 6). In particular, sulfur impurities of $0.14 \% \mathrm{~S}$ and phosphorus $0.38 \%$ $\mathrm{P}$ are concentrated in the carbide layers, which significantly affect the carbon liquation during the crystallization of the ingot.

For a more profound understanding of the phase structure, it was decided to carry out $\mathrm{x}$-ray phase analysis of samples from genuine Damascus steel type Ds15P. In Figure 7 shows the XRD pattern indicating ferrite (iron $\alpha$-Fe) and cementite (carbide iron $\mathrm{Fe}_{3} \mathrm{C}$ ) phases. The volume ratio between the ferrite and cementite is not possible to determine due to the imposition of all the diffraction lines of ferrite on the diffraction lines of cementite. Intermediate phases such as iron phosphide or residual austenite, which can be formed during the

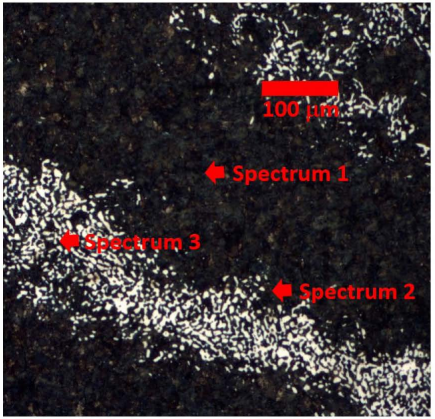

\begin{tabular}{|c|c|c|c|c|c|}
\hline \multirow{2}{*}{ Spectrum } & \multicolumn{5}{|c|}{ The content of chemical elements, \% } \\
\cline { 2 - 6 } & $\mathrm{C}$ & $\mathrm{Si}$ & $\mathrm{P}$ & $\mathrm{S}$ & $\mathrm{Fe}$ \\
\hline Spectrum 1 & 0.86 & 0.03 & -- & -- & 99.11 \\
\hline Spectrum 2 & 3.54 & 0.16 & 0.20 & -- & 96.10 \\
\hline & & & & & \\
\hline Spectrum 3 & 4.13 & 0.18 & 0.38 & 0.14 & 95.18 \\
\hline
\end{tabular}

Figure 6. Analysis of dark and light layers of the genuine Damascus steel (Ds15P).
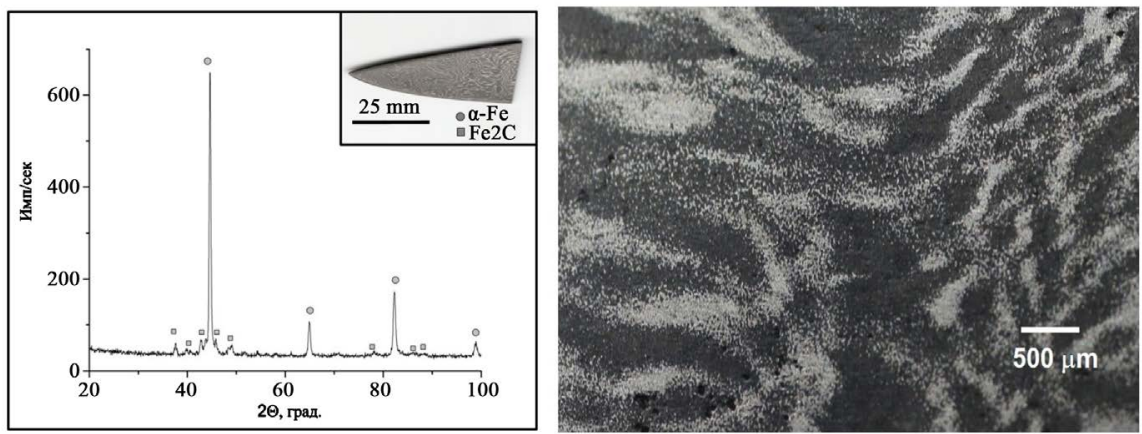

Figure 7. X-ray diffraction diagram and macrostructure of genuine Damascus steel (Ds15P). 
crystallization of ingot, were not detected by $\mathrm{x}$-ray phase analysis. This is probably due to the fact that in the process of thermodynamic treatment, phosphorus, with an average mass fraction of about $0.19 \%$, is able to completely dissolve in ferrite without forming a phosphide eutectic. As a result, as the impurity phosphorus greatly distorts the crystal lattice iron suppressing the formation of austenite during heat treatment.

According electron microscopy (Figure 8(a) and Figure 8(b)) it has been found that the matrix in the genuine Damascus steel Ds15P is a lamellar troostite with an interlamellar spacing of not more than $100 \mathrm{~nm}$. Lamellar troostite is formed because of isothermal quenching, for example, in superheated lead to $400^{\circ} \mathrm{C}$ or in molten fat at the temperature $200^{\circ} \mathrm{C}$. Thus, the microstructure of genuine Damascus steel Ds15P is a "troostite hardening", with an interlamellar spacing of about $0.1 \mu \mathrm{m}$, in which there are oblong particles of excess cementite with an axis ratio of $1 / 3$.

Let us consider in more detail the carbide layer of genuine Damascus steel, in which most of the carbides have an oblong shape. The elongated particles of excess cementite with an axis ratio of $1 / 3$ are the main distinguishing feature of genuine Damascus steels from the excess carbide phase of modern carbon Tools steels. The oblong form of excessive cementite was mentioned in the works, in which the genuine Damascus blades were studied with a significant excess of phosphorus admixture from $0.12 \%$ to $0.22 \%$ [1]-[7]. This form of secondary cementite is absent in the works on the plasticity of high-carbon steels such as UHCS, containing from $1.0 \%$ to $2.1 \%$ carbon [8] [9]. This form of secondary cementite has not been found in the works on the formation of the structure of high-purity Bulat steel type BU22A [10]-[15].

The dimensions of oblong carbides in the cross section area about 3.4 microns, and in the longitudinal section do not exceed $9-12$ microns. The chemical composition of the isolated excess oblong carbides showed that they have somewhat inflated carbon values of about 7.06\% C (Spectrum 1 in Figure 9), compared with cementite $6.67 \% \mathrm{C}$, indicating imperfection of the crystal lattice of these carbide formations.

The steel matrix, in which the oblong excess carbides are located, is heavily contaminated with harmful impurities such as sulfur of about $0.14 \% \mathrm{~S}$ and

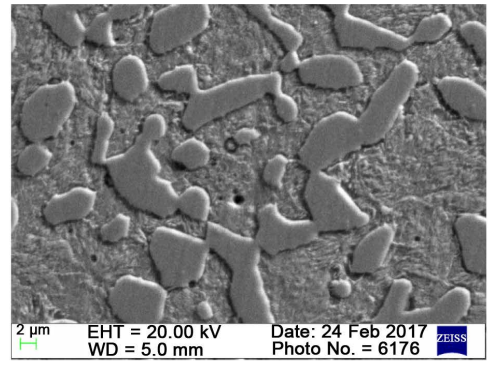

(a)

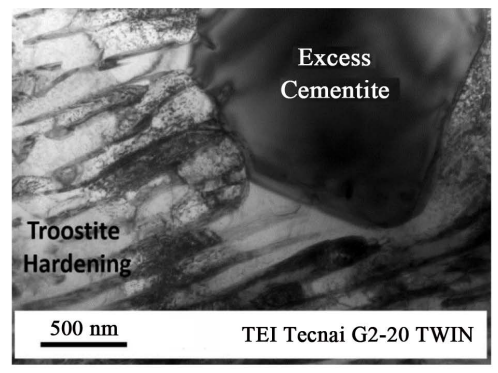

(b)

Figure 8. The microstructure of the genuine Damascus steel (Ds15P): (a) Scanning electron microscopy; (b) Transmission electron microscopy. 

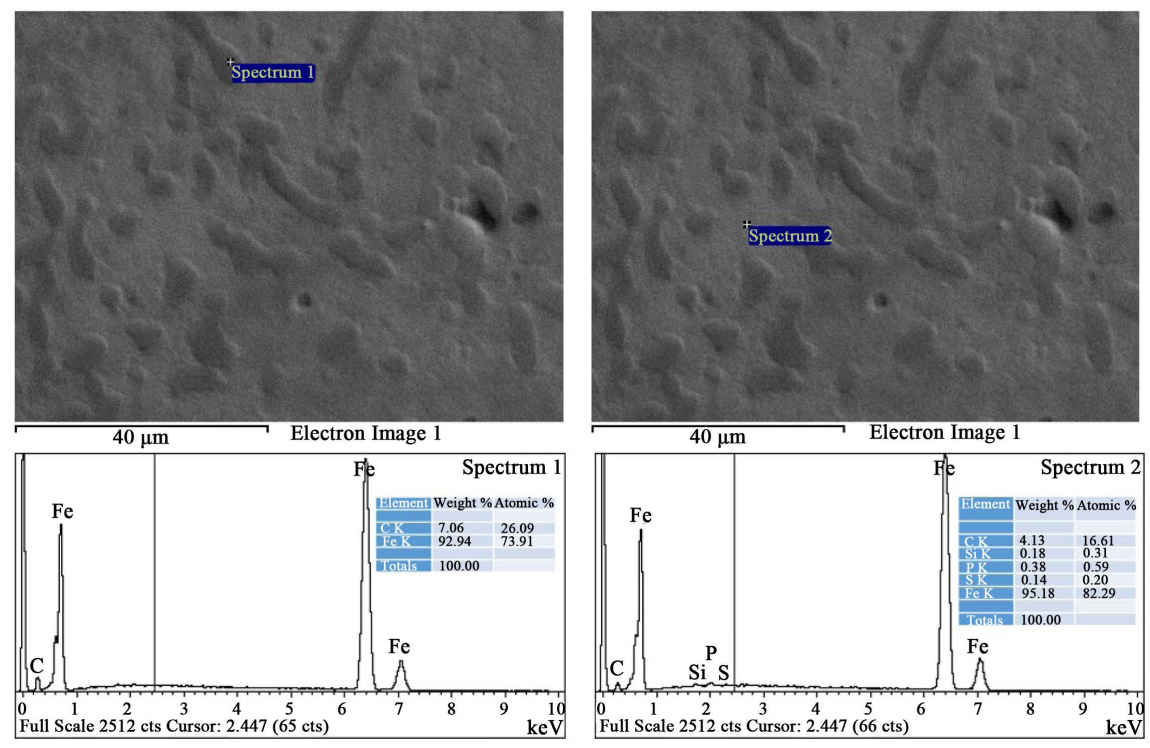

Figure 9. Composition of the main structural phases of genuine Damascus steel: Spectrum 1-Oblong carbide cementite; Spectrum 2-Troostite matrix.

phosphorus of about $0.38 \% \mathrm{P}$ (Spectrum 2 in Figure 9). The excessive amount of phosphorus and sulfur impurities in the steel matrix not only affects the carbon segregation during the primary crystallization of the ingot, but also influences the formation of carbides of an oblong shape during secondary crystallization during plastic deformation by forging.

In the areas adjacent to the elongated carbides, phases of residual austenite are observed. However, their volume ratio is so small that this phase can be neglected in further consideration of the structure of genuine Damascus steel (Figure 10).

Detailed consideration of oblong carbides revealed that these formations are not monolithic. The carbides microstructure consists of individual particles cementite in the form of "pebbles" (Figure 10(a) and Figure 10(b)). Individual cementite particles are tightly coupled to each other. Large oblong carbides in the deformation process can be divided into separate parts, according to the zones of conjugation of oblong cementite particles (Figure 10(a) and Figure 10(b)). They are radically different in morphology from Widmannstatten cementite, globular cementite, carbides cementite network and faceted excess carbides. From our point of view, oblong carbides cementite it should be considered a separate form of cementite inherent in genuine Damascus steels.

There are several different opinions about the nature of the formation of carbide layers in genuine Damascus steels, containing from $1.1 \%$ to $2.1 \%$ carbon. Some of them are reduced to the fact that the carbide layers are formed because of low-temperature forging in the range $650^{\circ} \mathrm{C}$ to $850^{\circ} \mathrm{C}$. In this temperature range, excess secondary cementite does not dissolve in austenite. In the process of low-temperature forging occurs crushing it into separate parts. Only in this range of forging temperatures, patterns are preserved in Damascus steel. Thus, 


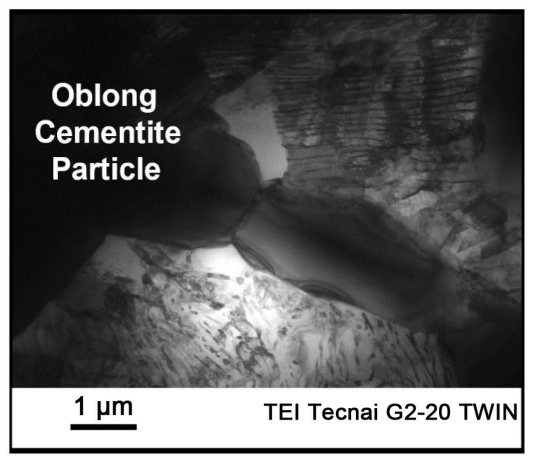

(a)

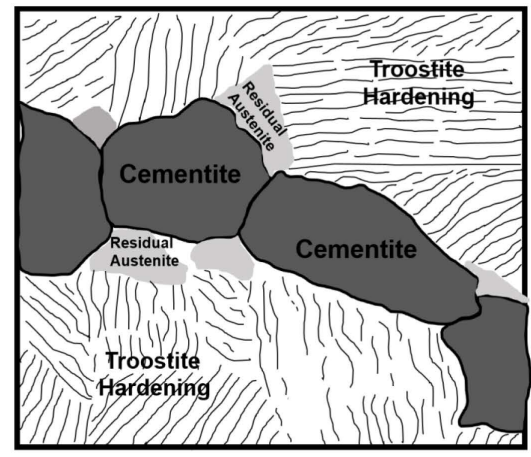

(b)

Figure 10. The microstructure of the oblong cementite particles: (a) transmission electron microscope; (b) schematic of oblong carbide.

according to the authors [16] [17] [18] [19] [20], the excess carbides in the genuine Damascus steel is a globular shards of fragmented cementite network. The formations of such structures are described by the mechanism of Wadsworth-Sherby [20].

Another opinion on the nature of the formation of carbide layers is that large oblong carbides formed during the crystallization of the wootz ingot. It is assumed that in the process of crystallization of the ingot in interdendritic zone occurs a segregation of the impurities phosphorus. At isothermal exposure, these areas are saturated with carbon up to the eutectic state [1] [5] [21]. In their opinion, with further cooling of the ingot in these interdendritic zones, are formed primary carbides of cementite not in the form of ledeburite, but in the form of massive isolated particles cementite. The formation of excess primary carbides in the form of massive particles cementite during the crystallization of wootz ingot is explained by the mechanism of Verhoeven-Pendray [21] [22].

It was decided to confirm or refute these hypotheses during the reconstruction of the original structure of genuine Damascus steel. For this wootz ingots were prepared by crucible melting with the addition of phosphorus-containing additives. The admixture of phosphorus, having a high coefficient of liquation, contributed to the process of carbon segregation in the interaxial intervals of dendrites. In the process of cooling of the ingot in the interdendritic zone were formed oblong carbides (Figure 11(a)). Probably, the morphology of carbide formations depends not only on the parameters of forging and heat treatment, but also from chemical processes occurring on the border of oblong carbides and pearlite matrix. In this zones there is of phosphide eutectic (Figure 11(b)).

For a more complete flow process, segregation of impurities, a wootz ingot was annealed long in a furnace for at least 5 hours at a temperature of $1150^{\circ} \mathrm{C}$. To prevent decarburization cast samples were annealed in ceramic crucibles. At such isothermal exposure, the solidus line, in the iron-carbon state diagram, shifts to the left up to the eutectoid point corresponding to about $0.8 \%$ of carbon. Axial areas of austenite dendrites were released from impurities to hundredths and thousandths of percent, which leads to an increase in deformation 


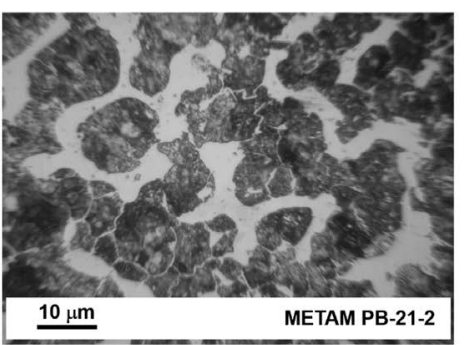

(a)

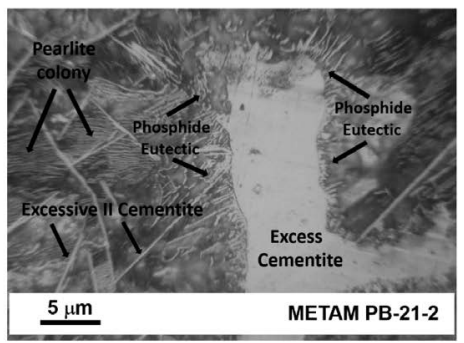

(b)

Figure 11. The microstructure of the cast wootz ingot: (a) Primary carbide heterogeneity of the wootz ingot (light areas); (b) The oblong carbide with zones there is phosphide eutectic.

plasticity under normal forging conditions. The interdendritic zone is saturated with excess carbon and impurities phosphorus, silicon and sulfur. Thus, interdendritic zone represent to the pre-eutectic white cast iron. The crystallization point in the interaxial areas is reduced to a temperature of eutectic decay corresponding to about $1147^{\circ} \mathrm{C}$. Further cooling of the wootz ingot can occur in an accelerated mode.

The subsequent forging of the annealed wootz ingot occurred at a temperature above $\mathrm{A}_{\mathrm{CM}}$ at $30^{\circ} \mathrm{C}-50^{\circ} \mathrm{C}$. The proof of this statement is the complete absence in the structure of the fragments of cementite, arising from the crushing of the excess carbide phase in the process of low-temperature forging. Low speed of diffusion of phosphorus in austenite matrix contributes to the slow decay of the resulting segregation of carbon in interdendritic intervals, which can significantly increase the temperature of heating for forging, without loss of carbide heterogeneity.

As a result, the microstructure of the carbide layer in genuine Damascus steel consists of oblong cementite particles located in the pearlite (troostite) matrix (Figure 12(a)). This conclusion is confirmed by the photography of the fracture of the carbide layer is made on the scanning electron microscope (Figure 12(b)). Thus, from our point of view, the oblong form of cementite is a distinctive feature of high-carbon steels with high phosphorus content. Tenths of a percent of phosphorus impurities not only contribute to the segregation of carbon in the interaxial areas of dendrites, but also forms a cementite in the form of massive oblong carbides.

We believe that the formation of oblong carbides in genuine Damascus steel occurs by the mechanism of Verhoeven-Pendray [21] [22]. That is, when large oblong carbides were formed during the crystallization of the wootz ingot. Long-term high-temperature annealing increased structural heterogeneity. Forging the blade took place in the temperature range from $940^{\circ} \mathrm{C}$ to $740^{\circ} \mathrm{C}$. In this temperature range, the carbide heterogeneity acquired a layered texture. It is noticed that some part of small cementite particles dissolving in austenite. At the same time, they again released in the process of deformation in the form of oblong carbides of smaller size.

By the mechanism of Wadsworth-Sherby [20] is the place to be in carbon 


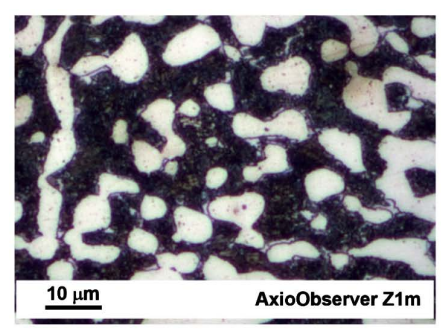

(a)

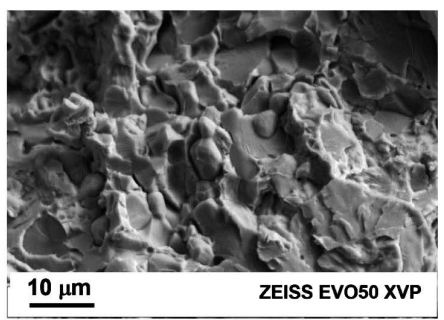

(b)

Figure 12. The microstructure of the forged wootz ingot: (a) Carbide layer after forging (optical microscopy); (b) Fracture of carbide layer (scanning microscopy).

Tool steels type y15A. In such steels, the excess cementite is completely dissolved in austenite at the temperature of heating for forging equal to about $940^{\circ} \mathrm{C}$. Secondary allocation of the excess cementite from the deformed austenite is in the form of spheroids evenly is distributed along the entire of the blade knife. For modern cutting tools, this structure is ideal. However, it does not correspond to the macrostructure of genuine Damascus steel. Therefore, to obtain patterned blades knife from steel $\mathrm{Y} 15 \mathrm{~A}$ must be forged in the temperature range just above $723^{\circ} \mathrm{C}$, that is, in the range $850^{\circ} \mathrm{C}-650^{\circ} \mathrm{C}$. As a rule, the patterns in such blades knife are small, and the matrix has a grayish tint.

Analyzing the above, we believe that the increased content of phosphorus in genuine Damascus steel explains the mechanism of formation of the macrostructure visible on the frontal surface of the blade knife in the form of a pattern "Kara-Taban" (Figure 13(b)). The pattern is formed in the process of forging an inhomogeneous dendritic structure of the ingot. The development of carbide heterogeneity is favored by the segregation of phosphorus impurities in the interaxle areas of dendrites. Elongated dendritic axes and interaxial zonas, because of the forging of the wootz, form a set of parallel layers (fibers) in the longitudinal and transverse section consisting of oblong cementite carbides.

In the process of forging ingot on the frontal surface of a steel strip are formed of the convexity and concavity, resembling topographic contour (Figure 13(a)). Near the local maximum (convexity) and the local minimum (concavity), the contour of the carbide inhomogeneity acquires elliptical of the lines pattern. Near the geometric saddle, the contour of the carbide inhomogeneity is a set of hyperbolic lines pattern. After polishing and etching in a $4 \%$ solution of nitric acid on the surface of the blade knife a light contour of carbide heterogeneity appears on a dark background of the troostite matrix, resembling a pattern " $\mathrm{Ka}$ ra-Taban" (black-shiny).

According to collectors of edged weapons, many genuine Damascus steel, along with a beautiful large pattern such as "Kara-Taban", have high hardness, reliability and cutting ability. Despite all the achievements of metallurgy in recent years, there is a strong opinion that the blades of modern carbon Tool steel have lower properties than the blades of genuine Damascus steel. The question arises whether the blades made of genuine Damascus steel have always been so good in operation, or is it just a beautiful legend? 


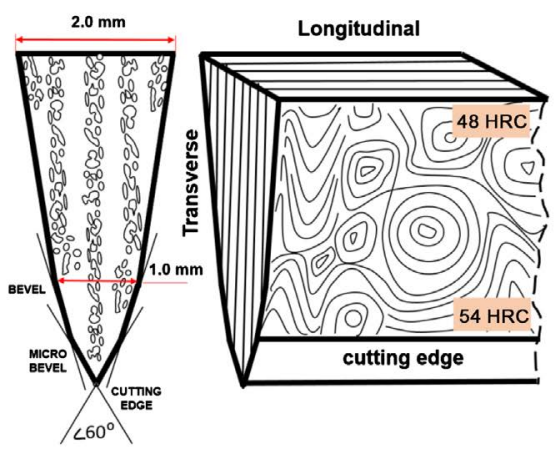

(a)

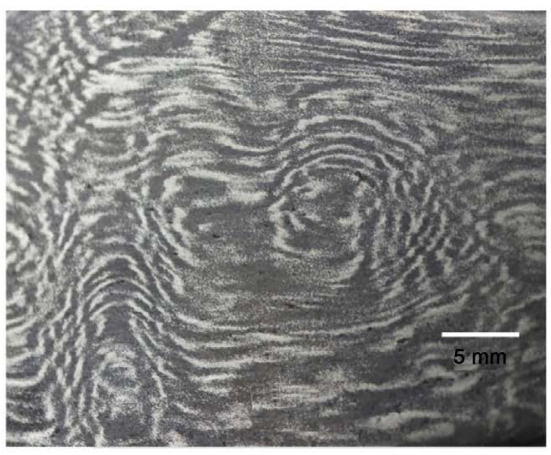

(b)

Figure 13. Scheme of the blade knife (a) and patterns genuine Damascus steel (b).

Back in the XI century, the Khorezm scientist Al-Biruni (1038) [23] drew attention to the fact that the blades of the Indo-Persian steel break when struck in the cold. Professor Gaev (1956) confirmed the low level of cold brittleness in work [1], who studied the saber blade of the XVIII century from the collection of the State Hermitage museum. Combat Damascus blade containing $1.97 \%$ carbon and $0.136 \%$ phosphorus from the impact was broken at the hilt and welded with iron. Today we know that a characteristic feature of high-carbon phosphorous steels is the reduction of impact strength at low temperatures (cold brittleness).

One of the first conducted bending tests genuine Damascus steels was the Austrian Metallurgist Zschokke (1924) [24]. The studied samples of genuine Damascus steel of content $1.342 \%-1.874 \%$ carbon with increased content of $0.086 \%-0.172 \%$ phosphorus; not all other elements exceeded hundredths of a percent. The results of static tests led him to a paradoxical conclusion. Static bending properties of ancient Damascus swords were inferior to the industrial bladed steel, made in Solingen. In his opinion, a huge impact on the reduction of the mechanical properties of genuine Damascus steels affected phosphorus, which is present in a significant amount in all the samples.

Checked in detail out the main findings of Zschokke of the American researchers Verhoeven and Jonas (1987) [2]. They studied in detail the influence of various impurities on the formation of patterns in genuine Damascus steel. Clearly show the possibility of formation of carbide strips during forging. Form the main features inherent in the Damascus steel. As a result, a team of authors from the United States managed to develop a method of reproduction of Modern Damascus blades without harmful phosphorus impurities.

Great job, for understanding the structure and properties genuine Damascus steels, held Dr. Taganov and PhD. Kalinin (2009) [5] [6], examining dozens of Indo-Persian blades, collected by expeditions of the Russian Geographical Society. In their opinion, the abnormally high content of phosphorus in genuine Damascus steel explains the mechanism of formation of a pattern such as " $\mathrm{Ka}$ ra-Taban" (black-shiny). The values of the mechanical characteristics of genuine Damascus blades reach no more than $75 \%$ of the properties of modern carbon Tool steels, which have no more than $0.01 \%$ phosphorus impurities in their 
composition.

Unlike our predecessors, we did not set ourselves the task to find out the complex of mechanical properties in static tests. Realizing that each blade knife has its own design features, we decided to limit ourselves to determining the hardness, determining the resistance of the cutting edge, determining the growth rate of the fatigue crack as a category of reliability under variable loads. The data were compared between layered samples of genuine Damascus steel type Ds15P (Figure 14(a)) and homogeneous samples of carbon Tool steel type Y15A (Figure 14(b)).

An interesting feature of the sample made of genuine Damascus steel is the heterogeneity of hardness indicators both on the butt and on the edge of the blade. On the butt of the blade, hardness does not exceed 48 HRC. On the cutting edge of the blade could reach $54 \mathrm{HRC}$. The hardness of the homogeneous sample of carbon Tool steel type Y15A was not less than 52 HRC. We can say that the average hardness of the samples of genuine Damascus steel and modern carbon Tool steel are the same. With this hardness, the samples have good elasticity with satisfactory resistance of the cutting edge. However, when the diameter of the diamond indenter imprint is about $2.5 \mathrm{~mm}$ when measuring Rockwell hardness and the size of the structural components in Damascus steel does not exceed $100 \mu \mathrm{m}$, then it is impossible to correctly determine the contribution of a structural factor to the integral hardness of the blade. We believe that this problem can be solved by measuring the microhardness.

Samples of modern carbon Tool steel (Y15A) have a homogeneous structure, that is, of the excess globular carbides are uniformly arranged in the troostite matrix (Figure 14(b)). The microhardness values are in the range of at least 400 - 600 HV (50 - 52 HRC) (Figure 15).

The structure in genuine Damascus steel (Ds15P) is most reminiscent of the Natural Composite Materials (NCM) created in the process of forging blades (Figure 14(a)). The microhardness distribution is the minima in the troostite layers from $390 \mathrm{HV}$ to $560 \mathrm{HV}$ and the maxima in the carbide layers from 820 $\mathrm{HV}$ to $1020 \mathrm{HV}$ (Figure 15). The distribution of microhardness in the samples of genuine Damascus steel confirms the self-sharpening effect of the blade edge, the so-called "micro-saw" (Figure 5(b)). The essence of the self-sharpening effect is a faster wear of the troostite layers compared to harder carbide layers.

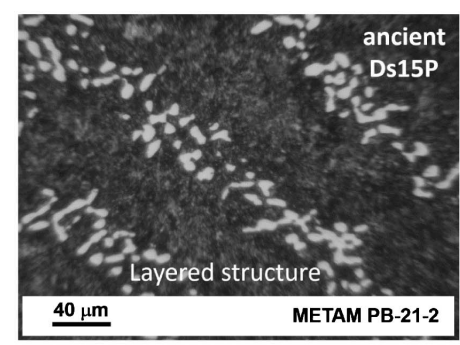

(a)

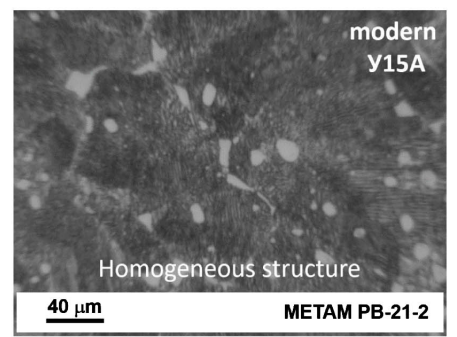

(b)

Figure 14. The microstructure of the steels: (a) genuine Damascus steel; (b) carbon Tool steel. 


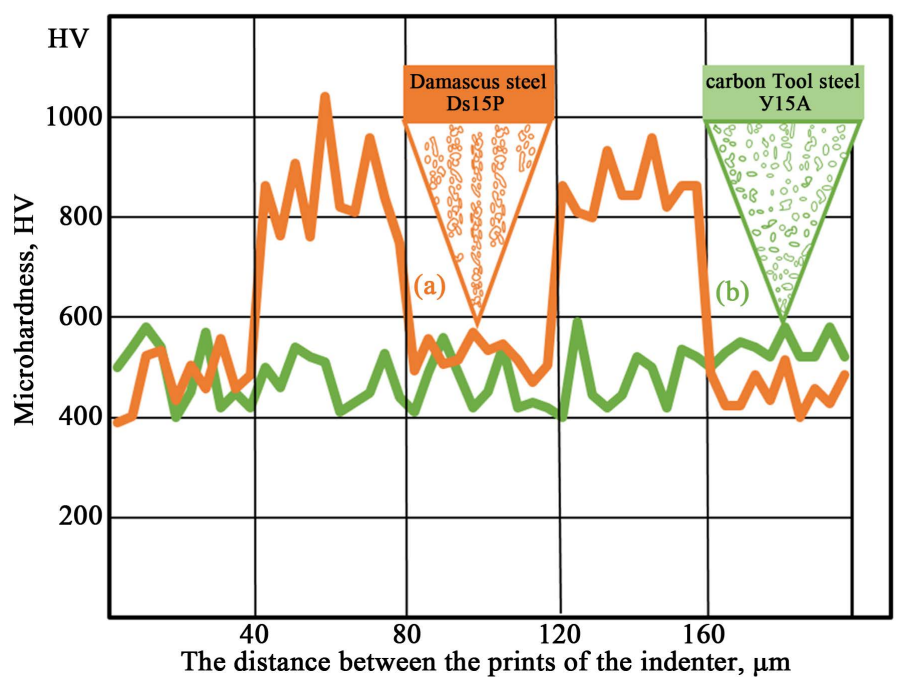

Figure 15. The microhardnessof the high-carbon steels: (a) Damascus steel (layered structure); (b) Carbon Tool steel (homogeneous structure).

A large divergence of the data on microhardness in the troostite layer from $390 \mathrm{HV}$ to $560 \mathrm{HV}$ is associated with uneven distribution of dissolved phosphorus. As the impurity introduction, phosphorous distorts the crystal lattice of the solid solution, which contributes to hardening of the ferritic in troostite colonies. The lowest hardness is observed in the middle of the troostite layer ( $390 \mathrm{HV}$ ), where the phosphorus impurity is minimal $0.02 \% \mathrm{P}$. In the transition zone, at the edge of the troostite layer microhardness increases to critical values $(560 \mathrm{HV})$, which is associated with an increase in phosphorus impurity to $0.2 \% \mathrm{P}$.

In carbide layers, due to the heterogeneity of the distribution of elongated carbides in the troostite matrix, the hardness depends not only on the increased phosphorus content of $0.4 \% \mathrm{P}$, but also on the effect of punching and damping of the diamond indenter. It is impossible to say which structural phase will be under the imprint of the diamond indenter (the "Iceberg" effect). Oblong cementite particle is able of pushed in the softer troostite the matrix, showing lower values of microhardness $820 \mathrm{HV}$. Conversely, in troostite the matrix of the carbide layer, the imprint of the diamond indenter can dampen, if under layer is hidden a particle of oblong carbide, which leads to an overestimation of the data on hardness $1020 \mathrm{HV}$. As a result, the average hardness in carbide layers is $920 \mathrm{HV}$, which is consistent with the data of Dr. Gaeva (770 - $1000 \mathrm{HV}$ ) [1] and Dr. Taganova (average $800 \mathrm{HV}$ ) [5].

Individual methods for testing the durability of the cutting edge are very much. However, there are no uniform rules for testing. Therefore, the test samples can be compared only with each other. To obtain reliable test results, the human factor was excluded. A load from $2 \mathrm{~kg}$ to $12 \mathrm{~kg}$ regulated the cutting force. Nature of the cutting was determined by the reciprocating mechanism as shown in Figure 3(a).

With a small force on the cutting edge equal to $2 \mathrm{~kg}$, genuine Damascus steel is showed of more than 2.5 times of the number of cutting, than modern carbon 
Tool steels (Figure 16(a) and Figure 16(b)). With minimal force on the cutting edge is the effect of "micro-saw" is likely. With $4 \mathrm{~kg}$ of force on the cutting edge 1.5 times (Figure 16(a) and Figure 16(b)) reduces the difference between of number of cutting of steel $\mathrm{y} 15 \mathrm{~A}$ and of number of cutting of steel Ds15P. With $5 \mathrm{~kg}$ of force on the cutting edge, of the number of cutting becomes the same. A further increase in the force on the cutting edge leads to the opposite result. From $6 \mathrm{~kg}$ to $12 \mathrm{~kg}$ of force on the cutting edge, carbon Tool steel is showed a more number of cutting on the $25 \%$ than in genuine Damascus steel (Figure 16(a) and Figure 16(b)). This fact is explained by the fact that with an increase in the force on the cutting edge on the test sample of genuine Damascus steel the main superiority of the layered structure, namely the "micro-saw" of the cutting edge, is lost.

In the ancient swords of genuine Damascus steel, the probability of the presence of hidden cracks increases dramatically. During operation, the microcrack is able to grow to the main crack, preparing the conditions for brittle fracture. Reducing the growth rate of microcracks can significantly increase the service life and reliability of the blade knife during operation. In this regard, of particular importance is the study of the "survivability" of blades knife with a homogeneous structure and with a layered structure.

In genuine Damascus steel type Ds15P with layered structure (Figure 17(a) and Figure 17(b)) fatigue microfracture originates in 2 times faster compared to homogeneous samples of modern carbon Tool steel type $\mathrm{Y} 15 \mathrm{~A}$. The origin of the fatigue crack depends on the defects of the structure, in particular, on the weakened interlayer boundaries.

Further tests showed that in a sample with a homogeneous structure ( $15 \mathrm{~A})$ the crack grows to a critical value in fewer cycles than genuine Damascus steel Ds15P (Figure 17(a) and Figure 17(b)). There are no significant obstacles on the way of crack growth in homogeneous structure. This means that in samples

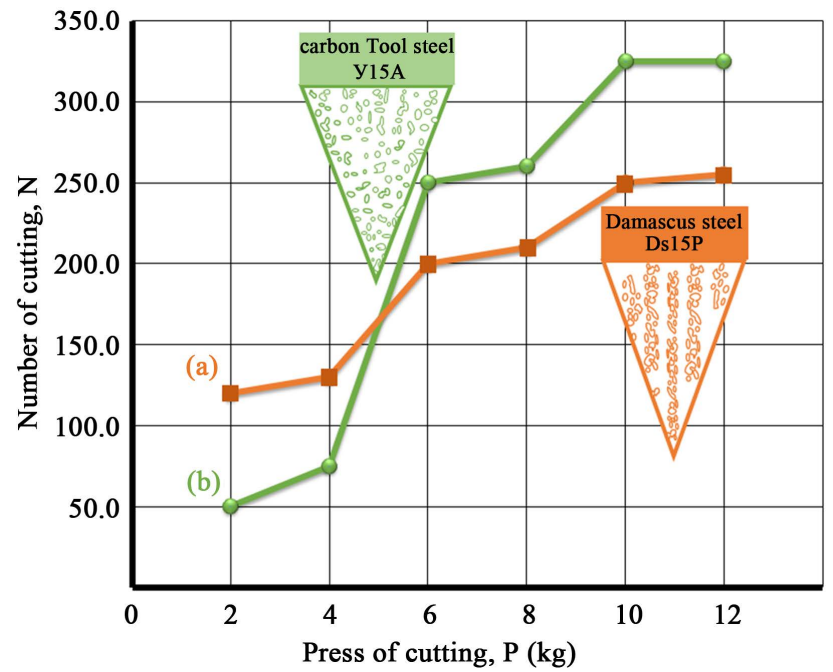

Figure 16. The resistance of the cutting edgein the high-carbon steels: (a) Damascus steel (layered structure); (b) Carbon Tool steel (homogeneous structure). 


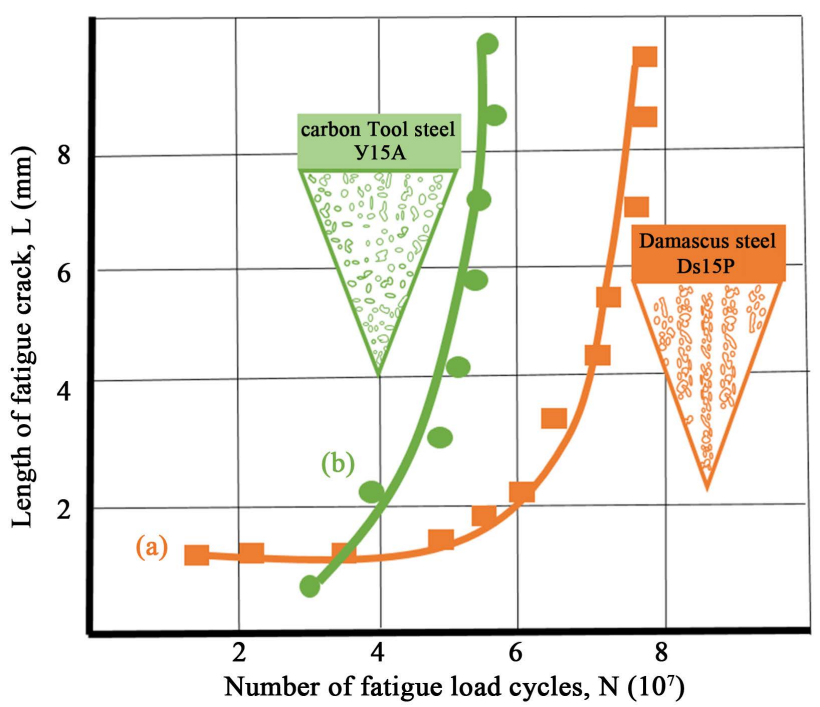

Figure 17. The fatigue of the cracking resistance in the high-carbon steels: (a) Damascus steel (layered structure); (b) Carbon Tool steel (homogeneous structure).

with a homogeneous structure is controlled of cracking resistance will occur at a lower critical length crack. Thus, for fracture of samples with a homogeneous structure is needed $2.7 \times 10^{7}$ cycles. For fracture of samples with a layered structure is necessary $6.2 \times 10^{7}$ cycles. We can say that in the blade knife of genuine Damascus steel (Ds15P), in terms of fatigue reliability ("survivability"), almost 2 times more service life than in the blade knife of modern carbon tool steel (Y15A).

The results can be explained by the favorable effect of the layered structure. In this structure, there are necessarily more weak areas in the interlayer boundaries. Growth of main crack leads to local delamination along the interlayer boundaries. The growth energy of the main of the crack is extinguished to zero. As a result, the mechanism of local lamination along the interlayer boundaries is realized enforce the crack to move in each individual layer. Previously, we have proved that the resistance to crack development increases sharply in multilayer steels, in which a layered structure is formed [25]. Thus, loss in cutting ability of a genuine Damascus steel compensates is increased the reliability ("survivability") of the blade knife with repeated fatigue loads.

\section{Conclusions}

The methods of spectral, $\mathrm{x}$-ray phase and microprobe analysis show that genuine Damascus steel is a high-purity unalloyed high-carbon steel with a high phosphorus content. It is revealed that phosphorus in an amount of from $0.1 \%$ to $0.2 \%$, having a high liquation coefficient, contributes to the process of segregation of carbon in interdendritic zone in the process of crystallization. Interdendritic zone formed carbon clusters, in the process of forging transform into oblong carbides cementite.

Oblong excess carbides on a morphological feature resemble a "pebble" with a 
thickening in the middle part. The sizes of the carbides in the cross section are about $3-4 \mu \mathrm{m}$ in the longitudinal cross section which does not exceed $9-12 \mu \mathrm{m}$; axis relation is $1 / 3$. The hardness of carbide layers is about $920 \mathrm{HV}$. The hardness of the troostite matrix was amounted about $475 \mathrm{HV}$.

Oblong carbide cementite is radically different in morphology from Widmannstatten cementite, globular cementite, carbides cementite network and faceted excess carbides. From our point of view, oblong carbides cementite should be considered a separate form of cementite inherent in genuine Damascus steels. We believe that the formation of oblong carbides in genuine Damascus steel occurs by the mechanism of Verhoeven-Pendray. That is, when large oblong carbides cementite was formed during the crystallization of the wootz ingot.

Cutting edge of the blade knife of genuine Damascus steel is nothing more than a "micro-saw" consisting of parallel carbide and troostite layers. At the little effort cut (to $4 \mathrm{~kg}$ ) ancient Damascus steel (Ds15P) shows a greater number of cuts than the modern instrument steel Y15A. With an increase, force on the cutting edge from $6 \mathrm{~kg}$ to $12 \mathrm{~kg}$ carbon Tool steel showed a more number of cutting on the $25 \%$ than in genuine Damascus steel. This fact is explained by the fact that with an increase in the force on the cutting edge the main superiority of the layered structure, namely the "micro-saw" of the cutting edge, is lost.

In the layered structure of genuine Damascus steel Ds15P, the fatigue crack propagation from the time of its occurrence until complete destruction occurs at a greater number of cycles than in the homogeneous structure of steel y15A. The blade knife of genuine Damascus steel, in terms of fatigue reliability (survivability), has almost 2 times longer service life than the blade knife of the modern carbon tool steel type $\mathrm{Y15 \textrm {A }}$. Thus, loss in cutting ability of a genuine Damascus steel compensates increased the reliability ("survivability") of the blade knife with repeated fatigue loads.

\section{Acknowledgements}

For assistance in conducting joint research works, the authors express his deep gratitude to the staff of the Department "Materials Science in Engineering" of Novosibirsk State Technical University.

\section{Conflicts of Interest}

The authors declare no conflicts of interest regarding the publication of this paper.

\section{References}

[1] Gaev, I.S. (1965) Damascus Steel and Modern Iron-Carbon Alloys. Metal Science and Heat Treatment, 9, 17-24. (In Russian)

[2] Verhoeven, J.D. and Jones, L.L. (1987) Damascus Steel, Part II: Origin of the Damask Pattern. Metallographe, 20, 153-180. https://doi.org/10.1016/0026-0800(87)90027-9

[3] Verhoeven, J.D. (2007) Pattern Formation in Wootz Damascus Steel Swords and 
Blades. Indian Journal of History of Science, 42.2, 559-574.

[4] Barnett, M.R., Sullivan, A. and Balasubramaniam, R. (2009) Electron Backscattering Diffraction Analysis of an Ancient Wootz Steel Blade from Central India. Materials Characterization, 60, 252-260. https://doi.org/10.1016/j.matchar.2008.10.004

[5] Taganov, I.N. and Kalinin, B.D. (2009) Influence of Phosphorus Impurity on the Technology of Damascus Steel. Metalworking, 2, 40-46. (In Russian)

[6] Kalinin, B.D. and Taganov, I.N. (2009) The X-RAY Fluorescent Analysis Use for Examination and Attribution of the Indo-Persian $17^{\text {th }}$ Century Genuine Damascus steel Arms. Analytics and Control, 13, 135-140. (In Russian)

[7] Sukhanov, D.A. (2018) Influence of Phosphorus Impurity on the Structure and Nature of the Destruction of the genuine Damascus Steel. International Journal of Engineering Technologies and Management Research, 5, 26-37.

[8] Sunada, H., Wadsworth, J., Lin, J. and Sherby, O.D. (1979) Mechanical Properties and Microstructure of Heat-Treated Ultrahigh Carbone Steels. Materials Science and Engineering, 38, 35-40. https://doi.org/10.1016/0025-5416(79)90029-6

[9] Oyama, T., Sherby, O.D., Wadsworth, J. and Walser, B. (1984) Application of the Divorced Eutectoid Transformation to the Development of Fine-Grained, Spheroidized Structures in Ultrahigh Carbone Steels. Metallurgical, 18, 799-804.

[10] Sukhanov, D.A. and Arkhangel'ski, L.B. (2016) Damascus Steel Microstructure. Metallurgist, 59, 818-822. https://doi.org/10.1007/s11015-016-0178-x

[11] Sukhanov, D.A., Arkhangelsky, L.B., Plotnikova, N.V. and Belousova, N.S. (2016) Morphology of Excess Carbides Damascus Steel. Journal of Materials Science Research, 5, 59-65. https://doi.org/10.5539/jmsr.v5n3p59

[12] Sukhanov, D.A. and Plotnikova, N.V. (2016) Wootz: Cast Iron or Steel? Materials Sciences and Applications, 7, 792-802. https://doi.org/10.4236/msa.2016.711061

[13] Sukhanov, D.A., Arkhangelskiy, L.B. and Plotnikova, N.V. (2017) Nature of Angular Carbides in Damascus Steel. Metallurgist, 61, 40-46. https://doi.org/10.1007/s11015-017-0451-7

[14] Sukhanov, D.A. and Plotnikova, N.V. (2018) Formation of Faceted Excess Carbides in Damascus Steels Ledeburite Class. Journal of Materials Science and Engineering $B, 8,36-44$.

[15] Sukhanov, D.A., Arkhangelskiy, L.B. and Plotnikova, N.V. (2018) Mechanism of $\mathrm{Fe}_{2} \mathrm{C}$ Type Eutectic Carbide Formation within Damascus Steel Structure. Metallurgist, 62, 261-269. https://doi.org/10.1007/s11015-018-0654-6

[16] Anosov, P.P. (1841) On the Bulats (Damascus Steels). Mining Journal, 2, 157-317. (In Russian)

[17] Tschernoff, D.K. (1899) Damask Steel. The Metallographist (Boston), No. 3. (In USA).

[18] Belaiew, N.T. (1918) Damascene Steel. Journal of the Iron and Steel Institute, 97, 417-437.

[19] Tavadze, F.N., Amaglobeli, V.G., Inanishvili, G.V. and Eterashvili, T.V. (1984) Electron Microscopic Studies of Damascus Steels. Bulletin of the Academy of Sciences of the Georgian SSR, 113, 601-604. (In USSR)

[20] Sherby, O.D. and Wadsworth, J. (1985) Damascus Steel. Scientific American, 252, 112-120. https://doi.org/10.1038/scientificamerican0285-112

[21] Verhoeven, J.D., Pendray, A.N. and Dauksch, W.E. (1998) The Key Role of Impurities in Ancient Damascus Steel Blades. Journal of Metallurgy, 50, 58-64. 
https://doi.org/10.1007/s11837-998-0419-y

[22] Verhoeven, J.D., Pendray, A.H. and Gibson, E.D. (1996) Wootz Damascus Steel Blades. Materials Characterization, 37, 9-22.

https://doi.org/10.1016/S1044-5803(96)00019-8

[23] Al-Biruni (1038) Meeting Details for the Knowledge of Jewelry. (Translated by Professor, A.M., Belenitsky, 1963). Publishing House of the Academy of Sciences of the USSR, Leningrad, 230-241.

[24] Zschokke, B. (1924) Du Damasse et des Lames de Damas. Revue de Métallurgie, 21, 635-669. https://doi.org/10.1051/metal/192421110635

[25] Sukhanov, D.A. (2012) The Structural Strength of Multilayered Steels (Welded Damascus Steels). Collection of Reports "State, Problems and Prospects of Restoration of Technology of Production of Damascus Steel, Bulat and Metal Composites”, Vol. 1, 83-104. (In Russian) 